\title{
THE MELTING OF FREE-DRIFTING ICEBERGS
}

\author{
by \\ D. S. Russell-Head \\ (Faculty of Engineering, University of Melbourne, Parkville, Victoria 3052, Australia)
}

\section{ABSTRACT}

Blocks of ice with the proportions of tabular icebergs have been observed melting in water of different temperatures and salinities. The sub-surface shape adopted by the blocks melting in water of the same salinity as sea-water was typically a 'bath-tub' one. The basal and meanside melt rates were of a similar value. The melt rates obtained in the laboratory for icebergs in water of a low temperature match those inferred from population studies of Antarctic icebergs. The melt rate is proportional to the water temperature above the onset of freezing raised to the power 1.5 and melt rates at $18^{\circ} \mathrm{C}$ are likely to be greater than one metre per day.

\section{INTRODUCTION}

In the analyses made by Hult and Ostrander (1973), Weeks and Campbell (1973), and Job (1978) of the feasibility of towing icebergs, one of the many parameters in need of numerical definition was the melt rate. The modification of the iceberg shape by melting during towing has an important effect on the prediction of towing forces required for given iceberg volumes. The type of harvesting scheme to be adopted at the final offshore site will depend on the natural melting characteristics of the delivered iceberg. It is particularly important to know whether the natural melt regime can be easily exploited or whether it is to be suppressed. The work reported here is a preliminary laboratory study into the melting oficebergs which are drifting freely.

\section{BACKGROUND}

In view of the technical and financial difficulties associated with a field study of full-scale icebergs, a laboratory programme was devised to ascertain the likely behaviour of free-drifting icebergs. A knowledge of the initial shapes of icebergs is useful when selecting a candidate for towing and an understanding of the melting at potential harvesting sites is a necessary precursor to the design of a successful harvesting scheme. The melting during towing might be seen as a modification of the freedrift situation.

The scaling of the melting of iceberg models in saline water appears to be complicated, and not the least reason for this might be the lack of a process model of ice-block melting.
Neshyba (1977), in his analysis of the upwelling due to iceberg melting was not sure that the basal melt was as important as the side me1t. As a result of their laboratory work, Huppert and Turner (1978) cast doubt on the ability of melt water to rise to the ocean surface. Griffin (1978) has presented an analysis of an iceberg slab during tow, but not for a static case, and Josberger (1978) conducted experiments on the convection next to vertical ice walls and correlated his results with field measurements on a small iceberg in the Labrador Sea.

The main purpose of the experiments to be described here was to model the melt process by placing blocks of ice of proportioned iceberg dimensions in an observation tank containing water of the same salinity as sea-water.

\section{EXPERIMENTAL METHOD}

Iceberg models of depth : width : length ratios of about $1: 2: 4$ were made by freezing layers of distilled water in zinc-plated steel moulds. The two moulds which were used had long dimensions of about $0.5 \mathrm{~m}$ and $1.0 \mathrm{~m}$, respectively. The ice blocks were melted out of their moulds when they were taken from the cold room, in the case of the small blocks, or out of a freezer box, in the case of the larger block (Fig.1).

Three sizes of models were used. Fullsize blocks from the moulds and smaller $0.1 \mathrm{~m}$ long blocks cut from ice made in the smaller mould formed a set covering one order of magnitude.

A glass tank $0.9 \mathrm{~m} \times 0.45 \mathrm{~m} \times 0.45 \mathrm{~m}$ accommodated the melting of the small- and medium-sized blocks, and a larger tank $2.0 \mathrm{~m} \mathrm{x}$ $1.2 \mathrm{~m} \mathrm{x} 1.0 \mathrm{~m}$ was constructed for melting the medium- and large-sized blocks. The small and large tanks had glass sides and base of thickness 6 and $25 \mathrm{~mm}$, respectively.

Commercially-available salt was mixed with public-supply water to model sea-water of varying densities. The large tank was fitted with a small domestic swimming-pool pump and filter and this served to mix the saline water thoroughly as well as to clean it.

Ice blocks were lowered into the tank of water and their dimensions during the melting sequence were recorded. The small iceberg models were measured with an acrylic rule placed 
against the melting block. The extremities of the large block were sighted along a set square held against the glass wall of the tank and the dimensions then taken from the markings so obtained. A tethering arrangement was used on the medium and large blocks to hold them centrally in the tank. Temperature measurements were made with a thermistor probe and quartz thermometer.

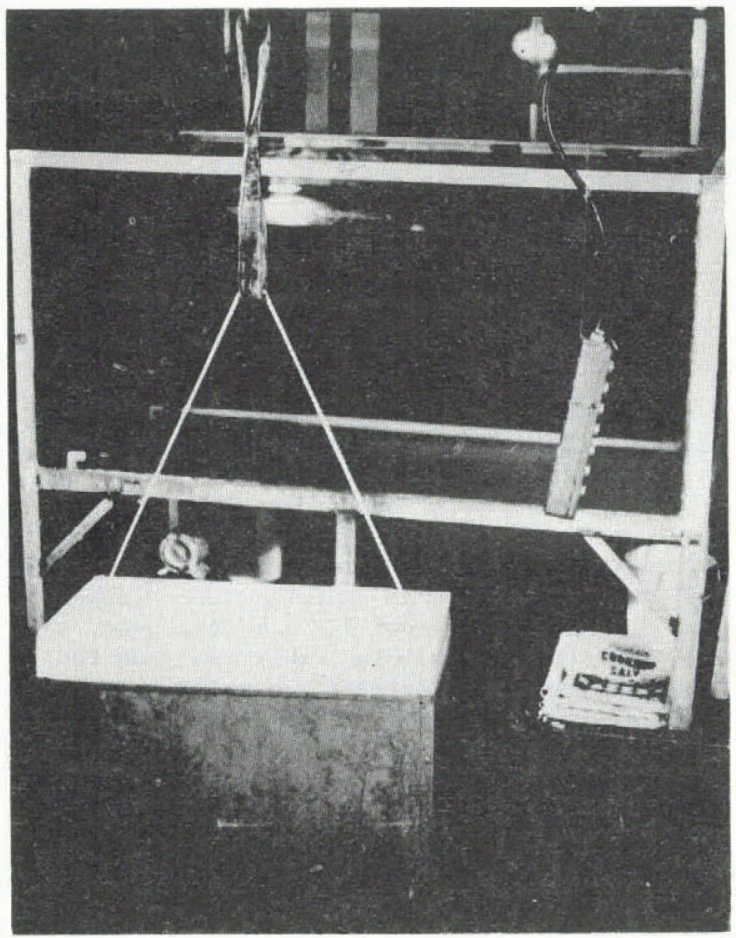

Fig.1. Ice block being removed from mould prior to immersion into the salt-water tank in the background. The lifting rope had been frozen into the $1 \mathrm{~m}$ long block

\section{SHAPE DURING MELTING}

The shapes of all the ice blocks that were melted in $35^{\circ} / \infty$ saline water adopted the same sequence of modification (Fig.2).

Melting occurred evenly over the base of the block and the sides tapered below the water line at an angle that steepened with time. An ice ledge was usually left above and just below the water line. The 'bath-tub' shape resulting from the melting was common to blocks of the three sizes melted in water of a wide temperature range (Fig. 3)

The basal melt rate is defined here as the rate of recession of the lower face of the ice block and the side melt rate as the mean rate of recession of the sloping walls of the block

(Fig.4). The basal melt rate is constant with time. The side melt situation is complicated and the rate may decrease with time. The effect is more pronounced with large blocks in a relatively small tank, since mixed melt water rises to the surface and forms a low-angle wedge tapering upwards and away from the block. This water floats above the more saline water and the demarcation between the two waters is well defined and readily observed.

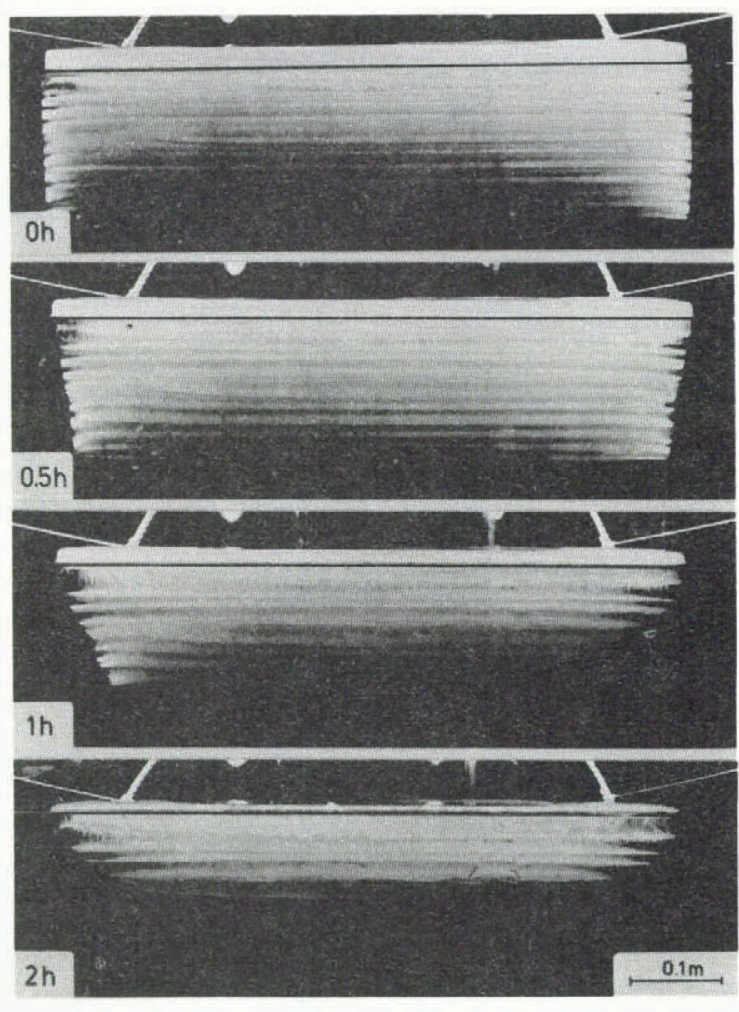

Fig.2. Sequence of shape development of the immersed portion of the iceberg model.

The mixed melt water is of a lower temperature than the initially-ambient water and, to an extent, it protects the ice wall from melting. For a large block in a small tank, the wedge of cold water is thick and offers considerable protection. The side melt rates of a medium and a large block melted in the large tank bear out this effect (Fig.4). The basal melt rates, on the other hand, are similar.

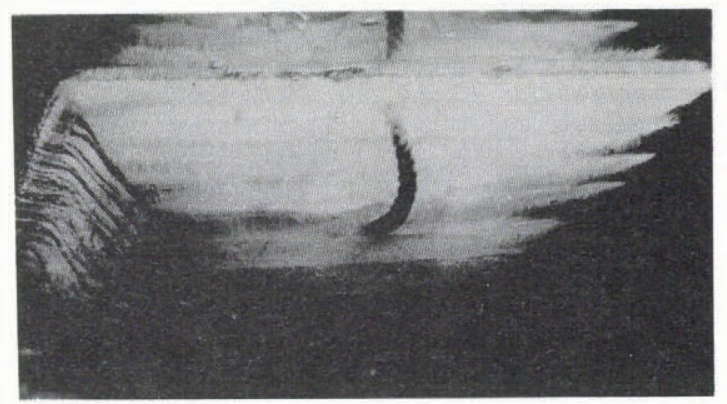

Fig.3. Under-water portion of a partially melted iceberg model exhibiting a relatively flat base and convex sides.

\section{DEPENDENCE OF MELT RATE ON SALINITY}

A number of small blocks were melted in water of varying salinities at a constant temperature (Fig.5).

The melting mode in fresh water is not the same as that in water of sea-salinity. In the former case, the mixed melt water sinks as it is 
more dense than the surrounding fluid and this change of direction of the melt water gives rise to a shape very different to that of a block in saline water. At some intermediate salinity, the buoyancy of the mixed melted water is minimized and the melt rates reflect this (Fig.5). The effect of salinity on the melt rates is not large for ice in water of salinity between $17.5 \%$ and $35^{\circ} \%$.

DEPENDENCE OF MELT RATE ON TEMPERATURE

The results of a number of tests in water of $35 \%$ salinity and temperatures ranging from near 0 to $20^{\circ} \mathrm{C}$ have been placed on a $10 \mathrm{~g}-10 \mathrm{~g}$ plot (Fig.6). Notwithstanding the scatter of the results, a power relationship appears to exist between the melt rate and the temperature difference between the water temperature and the

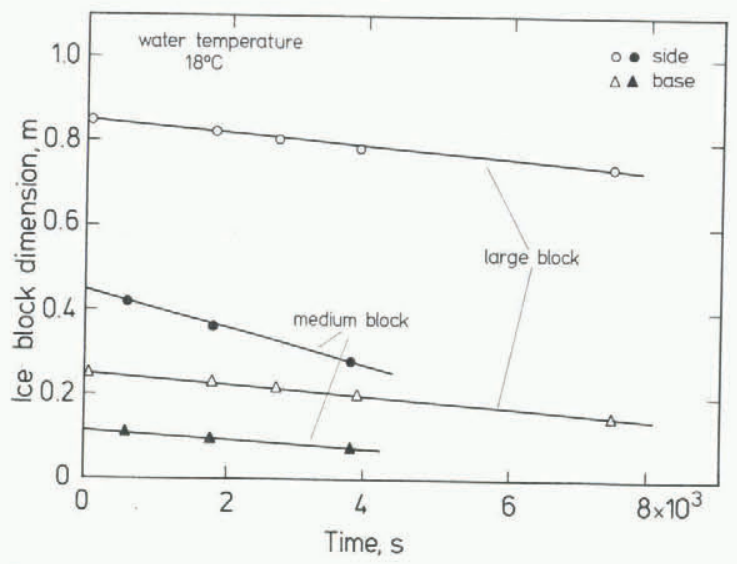

Fig. 4. Decrease in iceberg dimensions with time. The basal melt rates of the medium and large blocks are similar. The side melt rate of the large block is lower than that for the medium block due to the greater thickness of the melt plume next to the large block.

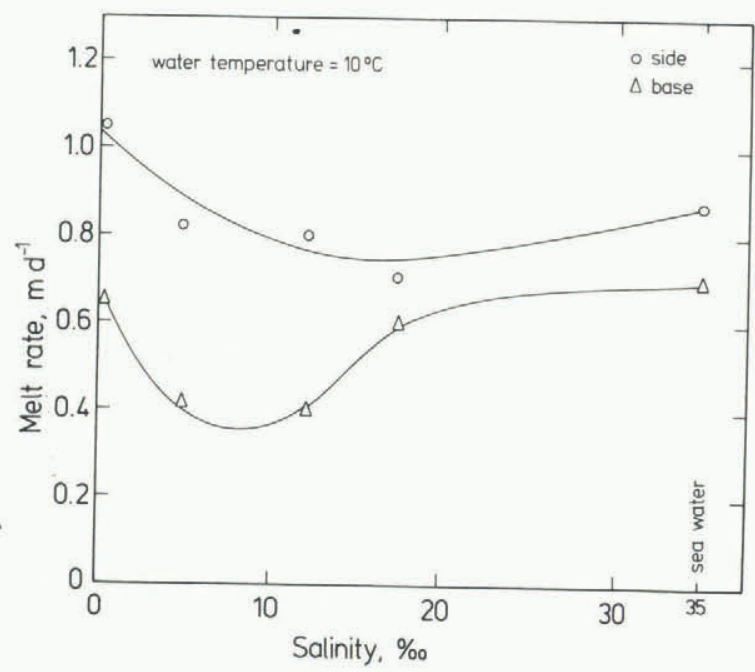

Fig.5. Variation of melt rates at constant temperature for different salinities. The minima probably occur when the mixed meltwater density is similar to the density of the ambient fluid.
Russell-Head: Melting of free-drifting icebergs

temperature at the onset of freezing of sea-

water $\left(-1.8^{\circ} \mathrm{C}\right)$

$$
\begin{aligned}
& R=1.8 \times 10^{-2}(\theta+1.8)^{1.5} \\
& \text { where } R \text { is the melt rate in } \mathrm{m} \mathrm{d}^{-1}, \\
& \text { and } \theta \text { is the sea-water temperature } \\
& \text { in }{ }^{\circ} \mathrm{C} \text {. }
\end{aligned}
$$

The experimental data fit well with the melt rates inferred for naturally deteriorating icebergs around Antarctica (Morgan and Budd, 1978) (Fig.6), and this lends credence to the validity of applying experimentally determined melt rates to the large iceberg scaletermined temperature water.

When considering the harvesting of icebergs, where the water temperature might be as high as $18^{\circ} \mathrm{C}$, the predicted melt rate is over one metre per day on the base and sides. It is unlikely that any harvesting scheme which works only on the upper surface of the iceberg can compete with this high rate of melting on the remaining five surfaces. It appears that some protection system will need to be employed at the harvest site.

\section{CONCLUSION}

The linear relationship between melt rate and temperature underestimates the melt rate of icebergs in $20^{\circ} \mathrm{C}$ water by a factor of two. Melt rates of more than one metre per day can be expected at potential offshore harvesting sites.

\section{ACKNOWLEDGEMENTS}

The author is grateful to Professors W.F. Budd and J.D. Lawson for numerous discussions on this subject. The staff Faculty Workshop are thankineering of the large observation tank.

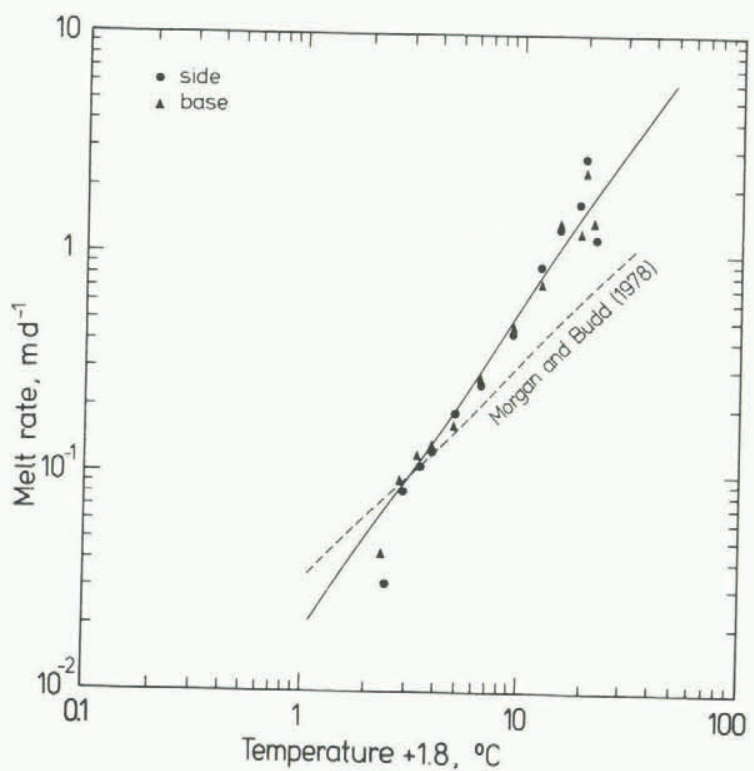

Fig.6. Temperature dependence of melt rate on sea-water temperature. The dashed line is the linear relationship of Morgan and Budd (1978) which was based on inferred melt rates of icebergs in Antarctic waters. 


\section{REFERENCES}

Griffin O M 1978 Heat, mass and momentum transfer effects on the ablation of icebergs in seawater. In Husseiny A A (ed.) Iceberg utilization. Proceedings of the first Intemational Conference, Ames, Iowa, 1977. New York, Pergamon Press: 229-244

Hult J L, Ostrander N C 1973 Antaretic icebergs as a global fresh water resource. Santa Monica, California, Rand Corporation (R-1255-NSF)

Huppert H E, Turner J S 1978 On melting icebergs. Nature 271(5640): 46-48

Job J G 1978 Yields and energetics in moving unprotected icebergs to southern continents. In Husseiny A A (ed.) Iceberg utilization. Proceedings of the first Intemational Conference, Ames, Iowa, 1977. New York, Pergamon Press: 503-527

Josberger E G 1978 A laboratory and field study of iceberg deterioration. In Husseiny A A (ed.) Iceberg utilization. Proceedings of the first Intemational Conference, Ames, Iowa, 1977. New York, Pergamon Press: 245-264

Morgan V I, Budd W F 1978 The distribution, movement and melt rates of Antarctic icebergs. In Husseiny A A (ed.) Iceberg utilization. Proceedings of the first International Conference, Ames, Iowa, 1977. New York, Pergamon Press: 220-228

Neshyba S 1977 Upwelling by icebergs. Nature 267(5611): $507-508$

Weeks W F, Campbe11 W J 1973 Icebergs as a fresh water source: an appraisal. Journal of Glaciology 12(65): 207-233 